\title{
Integrating nursing theory, practice and research through collaborative research
}

\author{
Mary Jean Denyes PhD RN \\ College of Nursing, Wayne State University, Detroit \\ Nancy A O'Connor MSN \\ Primary Care Nursing Service, Detrott Medical Centre, Detrott \\ Deborah Oakley PhD \\ School of Nursing, The University of Michigan, Ann Arbor \\ and Sharon Ferguson MSN \\ Primary Care Nursing Serotce, Detrout Medical Centre, Detrott
}

DENYES M J, O'CONNOR N A, OAKLEY D \& FERGUSON S (1989) Journal of Advanced Nursing 14, 141-145

Integrating nursing theory, practice and research through collaborative research

The advancement of professional nursing requires integration of theory, practice and research One realistic mechanism to achieve this integration is collaborative nursing research $A$ collaborative experience between clinical nurse specialısts and faculty researchers is described and evaluated The collaborative research project focused on contraceptive nursing care and self-care conceptualized within Orem's theory A major finding was that while job titles and settings of the participants differed markedly, role components were not disparate, rather, they were compatible and complementary The collaborative project strengthened both the theory base for a primary care nursing practice and the practice base for faculty research and theory development efforts

\section{INTRODUCTION}

Both nurse researchers and nurse clinicians must integrate theory, practice, and research if nursing is to achieve the scientific accountablity that characterizes a profession (Gortner 1974) Integrating all three elements in one professional role is rare, requiring nearly superhuman energy The result is a tendency to segment, rather than to integrate theory, practice and research One alternative is to foster collaboration between researchers and clinicians

The purposes of this paper are to describe a collaborative experience between clinical nurse specialists and

Correspondence Mary J Denyes College of Nursing, Wayne State Unubersty, 5557 Cass Avenue Detroit Michigan 48202, USA academic researchers, to evaluate its process, and to evaluate its impact on the integration of theory, practice and research Definitions of the degree of integration will be proposed and used to evaluate the case presented

\section{LITERATURE REVIEW}

Histoncally, collaboration between academicians and clinIcians has meant that the clinicians have acted as data collectors for academic researchers who designed, and often got credit for, the entire project Clinician and researcher roles were distunct and separate (Werley 1972) When the collaborative process went well, the roles were complementary, but role separation meant that there was little integration of theory, practice and research 
Recently, externally funded projects in the USA helped develop more mutually collaborative research (Lindeman \& Krueger 1977, Krueger et al 1978, Loomis \& Krone 1980) Now, collaboration is carned out in a vanety of ways, ranging from joint appointments (Hinshaw et al 1981) to consortiums (Bergstrom et al 1984, Zalar et al 1985) to academic or agency-based models for combining resources (Engstrom 1984) In today's nursing research environment, there is more diversity in the type and degree of collaboration when nurse clinicians and researchers are involved While the shared essence is still 'working together', collaborative relationships are now commonly developed to meet the specific needs of the team members and the project (Sweeney et al 1987) The result of today's diversity is an opportunity to share role functions in more than complementary ways

\section{Evaluation}

Evaluating the collaborative process is a new endeavour According to Suchman (1967), both process and outcome measures should be used in evaluation In the published literature, Lancaster (1985) has suggested measunng the six 'Cs' of the collaborative process contribution, communication, commitment, consensus, compatiblity, and credit Since role theory (Hardy \& Conway 1978) is so relevant, role functions can also be used to evaluate the collaborative process Those functions appropnate to this case are all charactenstics of an advanced nurse role assessing, mentonng, coordinating, managing, evaluating, and acting as change agent

For outcomes, Krueger et al (1978) suggest some summative evaluation measures of participants' satisfacthon However, since the outcome measure should depend on the purpose of the effort being evaluated (Suchman 1967), the appropnate outcome to study would be the degree to which the collaborative project affected the integration of theory, practice and research

\section{CASE}

In the fall of 1984 a small group of faculty at Wayne State Unversity College of Nursing, in Detroit, Michigan, USA, began meeting together to explore research designed to test Orem's theory of nursing Because of the perceived need for greater integration of theory, practice and research, the group was comprised of faculty members with primary interests in research and theory, and a clinical nurse spectahst from the Prinary Care Nursing Service at the Detroit Medical Centre, whose major interest was nursing practice Later the group expanded to include a faculty member from the University of Michugan School of Nursing, and doctoral students in nursing from both universities

The clinical nurse specialist from the primary care nursing service was one of nine master's prepared Amencan Nurses' Association (ANA) certified nurse practitioners in a group practice located in an ambulatory facility in the Detroit Medical Center All nine held adjunct faculty appointments in the Wayne State University College of Nursing The clinical nurse specialists had made a conscious decision to become involved with the faculty research group because they felt their practice could provide nich research data Participation in the group was seen by the clinical nurse specialists as a way to support the development of collaborative research Their implicit assumption was that the faculty researchers would design and conduct the research, while the clinicians would collect the data

In early summer, 1985, two faculty presented their recently submitted research proposal to the Orem study group The clinical nurse specialist was interested in the topic nursing interventions to support contraceptive selfcare The Primary Care Nursing Service used a model of practice that was consistent with Orem's (1985) self-care nursing framework, and contraception was one component of their care By the end of the summer, a collaborative research project was agreed upon

The project was a plot study designed to test the use of a pamphlet on contraceptive self-care and to pilot a questionnaire and a nursing assessment about the same topic The two faculty researchers needed to know the feasibility of using the pamphlet, determine the clanty of the questions, and obtain reliability data for the questionnaire The clinicians wanted to participate in research and obtain aggregate data about their group's nursing care The project reported here was chosen because it allowed flextbility None of the faculty researchers nor the clinical nurse specialists had release time for research So, instead of a full scale investigation requiring a large sample and complex research procedures, a small scale instrument development study was chosen That is, the project was talored to meet the researcher' needs and resources

Study procedures included use of the pamphlet with clients who came to the clinic specifically for birth control or with whom birth control was discussed dunng clinic visits The pamphlet was reviewed with the clients as part of the nursing care Later, each participating client completed a two-page questionnaire In addition, the nurse completed an overall nursing assessment rating of each client's self-care capabilities 


\section{EVALUATION}

As the research team developed and implemented the project, differing assumptions about the collaborative process were recognized Procedures did not necessanly fit established models For instance, not all of Lancaster's (1985) six essential 'Cs' charactenzed this project's collaboration at a uniformly high level For the case presented here, contribution, communication and commitment were not consistently operating at high levels, but rather varied widely over the 9 months of active collaboration

The group learned that careful attention to communication is critical to success When meetings were held regularly and frequently, mutual understanding of the goals, plans, problems and solutions was enhanced and data collection proceeded smoothly Discussions among the participants were especially valuable for standardizing the nursing care approach to using the contraceptive self-care pamphlet and to the nursing assessment of client self-care capability Closer monitoring, perhaps by a research assistant working directly at the clinic site, would have improved the data collection process so as to increase the sample size beyond the minimum number needed to direct changes in both the pamphlet and the questionnare

The other three elements of the Lancaster model (concensus, compatibility and credit) were attained at a high level Concensus was achieved without difficulty, and mutual compatibility was evident in the openness and flexibility of the team members Agreement regarding appropriate credit for each team member was readily achieved, possibly because each one felt rewarded by the professional growth expenenced through the collaborative process

It was also found that role functions were shared Each team member assessed the research problem, from her own perspective Each mentored the others by teaching and consulting The three team members with primary responsibility for the project coordinated and managed separate aspects of the study, from theory discussion to data collection, analysis and interpretation All participants actively evaluated data and discussed implications for changes in nursing practice Although prumary responsibility for vanous research activities shifted according to the task, the roles of clinical nurse specialist and faculty theorist/researcher were congruent as well as complementary The clinician and researcher roles remained separate and distinct, but role functions for the research project were shared

The result was a recognition by the clinucians that research functions were an integral part of both their own role descriptions and their own abulities They moved from a position of wishing to participate in research done by faculty, to one of commitment and capability to initiate and conduct research themselves Because the collaborative project had affirmed their ability to share role functions, they could integrate the overall researcher role into their own role definitions

\section{Achieving integration}

Since the goal, based on the work of the Orem study group, had been to integrate theory, practice, and research, the evaluative measure of interest is the degree of progress in achieving integration

Before proposing how to measure 'progress', the measure of 'integration' must be discussed If 'integration' can be measured as an ordinal variable, agreement could probably be reached on definitions for whether integration was absent, adequate or optımal No such attempt will be made here because the definitions for these categones would differ by the content area and the purpose, but for most situations of interest to nursing research, integration is probably somewhere in the 'adequate' category

It is much easier to measure improvements in integration First, change in one or more of the triad of theory, practice and research, would have to occur Then the change(s) would have to have strengthened one or more of the relationships

Change is relatively easy to measure reliably Were theoretical constructs added, subtracted, or understood in some different way? Was practice revised, or were research procedures or instruments changed? To establish a closer relationship between theory, practice and research, the changes in one would have to have been made specifically because of one or both of the others For example, statistical research and expert clinical practice can both lead to new theoretical insights

Were there changes in the theory component of this project, and if so, were these changes based on either the practice or the research? Given the pilot nature of the project, changes were anticipated primarily in the research component, but some of the most intriguing effects were in the theory component What were these changes, and were they based on either the practice or the research?

Collaborative discussions about the application of the theoretical concept of self-care incorporated the research data as they were analysed Group members were challenged to find that, from the 20 women studied, the clients perceived themselves to be comfortable with, and capable of, using their selected birth control method Almost $70 \%$ of the sample sard they felt very comfortable about using their method On average, they followed 
through on decisions they had made about using birth control $94 \%$ of the time, and felt pleased with their decisions about birth control $95 \%$ of the time The dinIclans and researchers came to view the clients' perceived comfort as one part of their self-care agency (self-care capability) While this new understanding did not change the theory itself, both academicians and clinicians better understood the human meaning of the theoretical constructs that had been used to develop the questionnaire

Additional findings were particularly important to the clinicians' practice All of the women reported that contraceptive self-care was encouraged by friends and partners Also, $32 \%$ had expenenced some physical side-effects of their method, and $37 \%$ feared some possible side-effects Finally, $42 \%$ sald they were not entirely comfortable about having sex

\section{Nursing care evaluation}

These data were used by the clinicians as one way to evaluate their own nursing care in a deliberate, purposeful, scientific manner (Hamnic 1985) They could document the proportion of clients who appeared to be confident about their contraceptive self-care capability, but might encounter self-care deficits when problems anse (for example, in connection with side-effects or their own sexuality) Orem's theory postulates that when the self-care demand of a person exceeds that person's agency, or ability, that person expenences a self-care deficit, and thus has a need for nursing $W_{1}$ ith data from this project, the clinicians realized they needed to focus their nursing care on expanding clients' self-care capabilities to overcome future problems as well as on the immediate choice of the most appropriate contraceptive method They also realized that they needed to adapt their care to deal with, and not exacerbate, unnecessary fears of side-effects Finally, the group of researchers and clinicians reinforced their knowledge that many women have substantial resources among their own frends and partners for the exercise of contraceptive self-care, just as Orem's framework would predict

The result is that the research provided impetus and direction for revising the clinic's family planning standards, so that they would more fully operationalize the concepts of self-care and the nursing care proposed by Orem The 'maps' (Visintainer 1986) used in nursing practice became more detalled, and thereby more useful

As expected, the pilot project also led to changes in the research procedures and content In the final project that followed, a research assistant is used for all study sessions so that recruitment does not have to be done by clinic staff The brochure was changed, some questionnaire items were reworded, and more complete, explicat directions were developed for the nursing assessment All of these changes grew from the collaborative project

\section{CONCLUSION}

This collaborative project served to strengthen both the theory base for the primary care nursing practice and the practice base for the faculty research and theory development efforts There is a greater integration of theory, practice and research The greatest effects were on the practice, and the research arenas, but the most intnguing effects were on the increased understanding of the major theoret1cal constructs, self-care and self-care agency Integration is still not optimal since theory needs to be understood more precisely and tested much more extensively, and the practice changes need to be continuously evaluated However, even this one small project has notably increased the adequacy of nursing theory, practice and research

\section{Acknowledgement}

The authors wish to acknowledge with gratitude the professional and personal support received throughout this project from the Orem Research Group at the College of Nursing, Wayne State University - truly a community of scholars

\section{References}

Bergstrom N, Hansen B C, Grant M, Hanson R, Kubo W, Padilla G \& Wong H L (1984) Collaborative nursing research anatomy of a successful consortium Nursing Research 33(1), $20-25$

Engstrom JS (1984) University, agency, and collaborative models for nursing research an overview Image 16(3), 76-80

Gortner S R (1974) Scientific accountability in nursing Nursing Outlook 22, 768

Hamric A B (1985) Clinical nurse specialıst role evaluation Oncology Nursing Forum 12(2), 62-66

Hardy ME \& Conway ME (1978) Role Theory Perspectives for Health Professionals Appleton-Century-Crofts, New York.

Hinshaw AS, Chance HC \& Atwood I (1981) Research in practice a process of collaboration and negotiation. Jourmal of Nursing Administration 11(2), 33-38

Krueger JC. Nelson AH \& Wolanun MO (1978) Nursing Research Development, Collaboration, and Utilization Aspen, Germantown, Maryland

Lancaster I (1985) The perils and joys of collaborative research what to look for - and what to avord - when putting together a research team Nursing Outlook 33(5), 231-232, 238

Lindeman C A. \& Krueger JC (1977) Increasing the quality, quantity, and use of nursing research Nursing Outlook 25(7), 450-454 
Loomis ME \& Krone KP (1980) Collaborative research development Joumal of Nursing Administration 10(12), 32-35

Orem DE (1985) Concepts of Practice, 3rd edn McGraw Hill, New York

Suchman EA (1967) Evaluative Research Russell Sage Foundatıon, New York

Sweeney M S , Gulıno C, Lora J M \& Small M A (1987) Collaboration in clinical research binational projects shed new light on old issues Journal of Professional Nursing 2(1), 28-38
Visintainer M A (1986) The nature of knowledge and theory in nursing Image 18(2), 32-38

Werley H H (1972) This I believe about clinical nursing research Nursing Outlook 20(11), 718-722

Zalar M.K. Welches LJ \& Walker D D (1985) Nursing consortrum approach to increase research in service settings Journal of Nursing Administration 15(7,8), 36-41 
This document is a scanned copy of a printed document. No warranty is given about the accuracy of the copy. Users should refer to the original published version of the material. 